\title{
Lady Kahhal, First Female Ophthalmologist and Medical Journalist in Iran
}

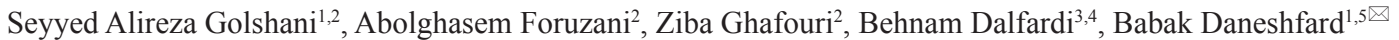

\author{
1. Research Center for Traditional Medicine and History of Medicine, Shiraz University of Medical Sciences, Shiraz, Iran \\ 2. Department of History, Faculty of Literature and Humanities, Shiraz University, Shiraz, Iran \\ 3. Student Research Committee, Shiraz University of Medical Sciences, Shiraz, Iran \\ 4. Research Office for the History of Persian Medicine, Shiraz University of Medical Sciences, Shiraz, Iran \\ 5. Essence of Parsiyan Wisdom Institute, Traditional Medicine and Medicinal Plant Incubator, Shiraz University of Medical Sciences, \\ Shiraz, Iran
}

\begin{abstract}
With the advent of constitutional revolution in Iran and the increase in people's knowledge, women's status changed and ultimately improved. Publishing newspaper was one of the women's attempts to keep their rights. Lady Somayyeh Kahhal was the first woman in this field, as well as ophthalmology in Iran. She published the first specialized newspaper for women in Iran under the title of Danesh (Knowledge). Lady Kahhal tried to disseminate information on women's rights, moral issues and also health and hygiene in her weekly-published newspaper. In this paper, we will review the remaining biographical information about Kahhal and will introduce her newspaper, Danesh. [GMJ.2015;4(2):129-32]
\end{abstract}

Keywords: Danesh Newspaper; Women; Ophthalmology; Journalism; Iran

\section{Introduction}

$\mathrm{A}$ rguing women's issues is not as easy as it seems to be. Throughout the history, the fundamental role of women which is, in fact, very important, usually has been neglected. However, with a short survey and analysis, the impression of women in the most important events of history will be revealed. From such an aspect, during contemporary century, the presence of women in Iranian society has become more prominent and they tried to seek their rights and increase women's literacy and awareness [1].

At the time of constitutional revolution, widespread political and cultural changes happened in Iranian society. Gradually, women did

\section{GMJ}

2013 Galen Medical Journal

Fax: +98 7312227091

PO Box 7461686688

Email:info@gmj.ir more prominent social and political activities and the press of that time, like Habl ol-Matin (published in Iran and India) by Sayyed Jalalal-Din Mo'ayyed-al-Eslam Kashani (18631930), Neda-ye Vatan (published in Iran) and Ana Daily (published in Turkish language), were supporting them [1]. At this point of time, Lady Somayyeh Kahhal played a major role in establishing women's rights and their related issues in Iranian community.

Kahhal began her activities with establishing a newspaper especially dedicated to women [2]. In addition to publishing one of the first specialized newspapers for women in Iran, Kahhal was the first female ophthalmologist in this country. Although some have rejected this claim, in this study, according to the evi-

\footnotetext{
Correspondence to:

Babak Daneshfard, Research Center for Traditional

Medicine and History of Medicine, Shiraz University of

Medical Sciences, Shiraz, Iran

Tel (Fax): (+98) 713 2345144-5

Email Address: babakdaneshfard@gmail.com
} 
dence and documents, we try to show whether she was an ophthalmologist or not. The second point of this paper is to explain the role of Kahhal's newspaper, as a medical encyclopedia, in familiarizing women with life and healthcare issues.

\section{Somayyeh Kahhal}

Unfortunately, little is known about the life of Somayyeh Kahhal. As it will be discussed below, most of such biographical information is from quotations of Kahhal herself and some other people who knew her.

Kahhal introduced herself in her newspaper, Danesh (Knowledge), as follows: "This little lady, doctor Kahhal, daughter of decedent Mirza Muhammad Hakim Bashi Jadid-ol Eslam ...". Her father, Yaghub Jadid-ol Eslam Hamedani, was from religious minorities of Hamadān (now West Iran) who chose Muhammad for his name after turning to Islam. Some have stated that Kahhal preliminarily learned medicine from her father and then practiced as an ophthalmologist [3].

Regarding title of doctor, Mohammad Sadr Hashemi (1905-1965) and Edward Browne (1862-1926) (Iranologist and British scholar) have said that lady Kahhal was the wife of doctor Hossein Khan Kahhal (died in 1950), the manager of Esteghlal-e Iran (Independence of Iran) newspaper, and giving this title to her is related to her husband and she herself was not really a doctor $[3,4]$. But, M. Mohit Tabatabaei (1902-1991) (researcher, historian and writer) explained in his book that lady Kahhal did not have any familial connection with Hossein Khan Kahhal. He said: “...The connection string between them was not familial, it was technical and both of them were ophthalmologists" [5].

Moreover, S. Babran (born in 1969) (an Iranian $\mathrm{PhD}$. in communication sciences) has said in her book that in some issues of the newspaper, announcements like the following can be seen: "Ophthalmologic office of this maid of people is in Khalilabad street and like the past, every day before noon except Fridays, I'm ready for visiting ophthalmologic patients." This statement can confirm that Kahhal herself was an ophthalmologist and she did not receive the title of lady doctor just because

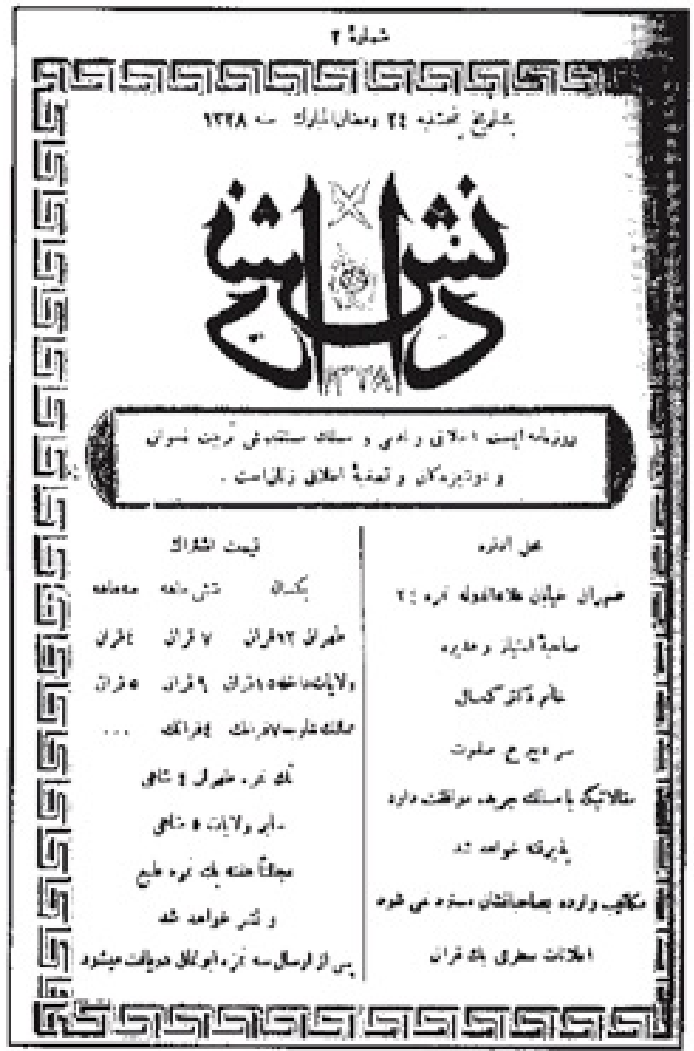

Figure1. Front page of second issue of Danesh newspaper belonging to $1910 \mathrm{AD} / 1328 \mathrm{AH}$.

of her husband who was a physician [1]. In addition to aforementioned statements, some contents of Danesh newspaper are helpful in responding this question. In this respect, a review of the aforenamed publication will show the fact that Kahhal had strict recommendations about healthcare of women and children in her newspaper and due to her acquaintance with principles of medicine and hygiene, she had described health issues with great details and accuracy. Furthermore, Kahhal introduced upbringing of children from birth as a solution to many social problems [1]. All these show that, in fact, Kahhal herself was a physician.

It has been said about lady Kahhal that she studied medicine with American missionaries and got their permission for treating people [1]. In this regard, Afarin Tavakkoli (born in 1979) ( $\mathrm{PhD}$ in history) has described a story. Although the source of her statements is not completely understood, reviewing a part of them is not without benefits: "She [Kahhal] 
had been the wife of a famous clergyman of that time and had done medical practice with his permission...". However, as the title of Kahhal's father was Hakim Bashi (Physician), there is a probability that she has learned preliminary medicine from her father. But usage of English words in healthcare texts of Danesh newspaper rather supports this probability that she learned medicine from Christian missionaries [6]. Hamadān was the third place after Oroumieh and Tabriz in which, American Christian missionaries attempted to establish hospitals, practice and educate modern medicine, in addition to their religious affairs [7, 8]. However, it is not clear that which one of these American missionaries has actually trained lady Kahhal in ophthalmology.

\section{Danesh Newspaper}

Danesh newspaper (Figure.1) was one of the first publications in Iran specifically established for women with the purpose of defense of their rights and demonstration of their true value and actual position [3]. Kahhal was concessionaire of this publication, the first number of which was released in 1910 [9]. It was a weekly newspaper that was printed with softcover format by lead printing in Tehran [3].

At present, of total 30 published issues of Danesh newspaper, 8 have been retrieved by Iranian National Library. Kahhal have published some topics of healthcare in issues $1,4,5,6$ and 25 of her newspaper, bearing these titles: Healthcare of Children, Suitable Nutrition of Children, Healthcare at the Time of Cholera Outbreak, Healthcare Wisdom of Mother for Her Children from Their Birth Time to the Growing Age, and Healthcare of Women [10].

Now we review the editorial of the first number of Danesh newspaper to get more familiar with this publication and the purpose of its publisher:

"In the name of God

It's not hidden from masters of knowledge and insight that creator of wisdom and sustainer of all creation has entrusted training of mankind -both male and female- to the efficacy and power of wisdom of mothers and has dedicated this gift to women. Since all newborns from their birth to the age of 10 learn ethics from mothers and copy their behavior, whenever mothers don't follow moral behavior, inevitably their descendants will be the same. So what we have to do for mothers to afford these responsibilities?" $[10,11]$

Then, Kahhal said about the aim of newspaper: "It's a newspaper about moral issues, housework, children and marital issues which are beneficial to the women and girls and it doesn't deal with politics." Such a sentence has been repeated in all issues of newspaper under its title [12]. As previously mentioned, focusing on healthcare issues was one of the most unique and remarkable aspects of this publication [1].

Unfortunately, Danesh newspaper was shortlived and after the publication of issue 30 , it was closed forever. The last issue was published one year after the first one in 1911 [1]. The reason of its closure is not clear; however, some have said it was due to the economic problems [2].

\section{Conclusion}

As mentioned in present article, lady Kahhal, as a writer, journalist, teacher and scholar who was the first female ophthalmologist in Iran, succeeded to establish one of the first specialized newspapers for women in Iran. She officially spoke on women's rights and their limitations in society for the first time. Her immense effort had a great influence on promotion of health and literacy of women and helped them find their real position in family and society.

\section{Conflicts of Interest}

Nothing to declare. 


\section{References}

1. Babran S. Journal of Women. Tehran: Payyam-e-Emroz Publication; 1952, pp 26-7. [In Persian]

2. Ansari S, Martin V. ed. Women, religion and culture in Iran. RoutledgeCurzon; 2002, pp 70-1. [in English]

3. Sadr Hashemi M. History of newspapers and magazines. 2th ed. Unwarranted; 1952, pp 297-9. [in Persian]

4. Browne EG. The press and poetry of modern Persia. 2th ed. Translated by Abbas Mohammad. Tehran: Alam Publication; 2007, p 562-3. [in Persian]

5. Tabatabaei M M. Analytical history of press in Iran. Tehran: Besat Publication; 1996, p 173. [in Persian]

6. Tavakoli A. "Women's Movement and the Media: 1332-1320," MA thesis, Supervisor: Gh. Vatandost. Department of History, Faculty of Literature and Human Sciences, Shiraz University, Shiraz, Iran; 2003, p 20. [in Persian]
7. Elder, John. History of American missions in Iran. Azari S. Tehran: Nur Jahan Publications; 1954, pp 49-83. [in Persian]

8. Ringer, Monica M. Education, keligion, and the discourse of cultural keform in Iran. Translation Haghighat-khah M. Tehran: ghoghnoos Publications; 2002, p 141. [in Persian]

9. Vatandost Gh, Shipary M, Tavakoli A. Iranian woman's constitutional publications. Tehran: Institute for Humanities Research and Development Publication; 2006, p 20. [in Persian]

10. Abhari M. introduced the first women's magazine in Iran. Journal of Book of the Month (General). 1999; 16(3): 6-9. [in Persian]

11. Lady Kahhal S. Danesh newspaper. 1910; 1(1): 2. [in Persian]

12. Dezham E, Mahjoub N, Bokaei L, Hashemi Bahramani F. First women. Tehran: Alam Publication; 2005, p 158. [in Persian] 